\title{
Fatigue life extension study in cast steel railway couplings used in freight trains
}

\author{
Morgado T. L. M. ${ }^{1,2}$ \\ ${ }^{1}$ Engineering Departmental Unit of Tomar Polytechnic Institute, Tomar, Portugal \\ ${ }^{2}$ CeFEMA - Center of Physics and Engineering of Advanced Materials, Lisbon University, Lisbon, Portugal
}

\section{Email address:}

tmorgado@ipt.pt

\section{To cite this article:}

Morgado T. L. M.. Fatigue Life Extension Study in Cast Steel Railway Couplings Used in Freight Trains. International Journal of Mechanical Engineering and Applications. Special Issue: Structural Integrity of Mechanical Components. Vol. 3, No. 2-1, 2015, pp. 1-6. doi: $10.11648 /$ j.ijmea.s.2015030201.11

\begin{abstract}
In this paper, fatigue life extension results from pre-existing surface defects in cast steel ASTM A148 90-60 of railway couplings, used in service in Portugal for coal transportation, are presented using two crack growth relationships (Paris equation and modified Paris equation). Fatigue lives were obtained and the results were discussed in terms of the threshold value for non-propagation cracks (modified Paris law) the initial value of the starting crack. It was found that for both crack growth relationships significant crack extension lives can be assumed. Therefore for these components and in this application damage tolerant procedure can be used with safety and this component can be kept in service provided appropriate inspection procedures are applied to detect and measure fatigue cracks. This will avoid early retirement from service of these components, since extension life can be assumed with safety.
\end{abstract}

Keywords: Fatigue Crack Growth, Life Extension, Paris Law, Modified Paris Law, Railway Component

\section{Introduction}

In 1961, Paris, Gomez and Anderson [1] suggested the relation between the crack extension per cycle $(\mathrm{da} / \mathrm{dN})$ with the maximum stress intensity factor $\mathrm{K}_{\max }$. Subsequently, Liu [2] work implied that the crack growth was a function of the stress intensity factor range $\Delta \mathrm{K}=\mathrm{K}_{\max }-\mathrm{K}_{\min }$. Also, Paris and Erdogan [3] proposed a similar relationship known as Paris equation, Eq. (1).

$$
\mathrm{da} / \mathrm{dN}=\mathrm{C} \Delta \mathrm{K}^{\mathrm{m}}
$$

where $\mathrm{a}$, is the crack size, $\mathrm{N}$ is the number of cycles, $\Delta \mathrm{K}$ is the stress intensity factor range, and $\mathrm{C}$ and $\mathrm{m}$ are coefficients related to material property experimentally determinate.

The relationship between crack growth per cycle and $\Delta \mathrm{K}$ has three distinct regions: region I where the crack growth is slow and several authors have introduced the concept of a fatigue threshold stress intensity factor range, $\Delta \mathrm{K}_{\mathrm{th}}$; region II is the region of Paris equation and its variants, is thought to hold; and region III, associated with rapid crack growth, tearing or static modes. Notice that the threshold strongly depends on the $\mathrm{R}$ ratio and this is a matter of further empirical equations that are omitted here for simplicity. For stage II,
Paris' law in Eq. (1) works correctly, up to deviations in region III, which in turn depend strongly on the R-ratio since the fracture mode becomes essentially static and governed by the maximum value of the stress intensity factor. The curve exhibits a rapidly increasing growth towards ductile tearing and/or brittle fracture, and a possible transition curve was proposed first by Foreman et al. [4].

The coefficients $\mathrm{C}$ and $\mathrm{m}$ are both random variables. In 1987, Ichikawa has reported that $\mathrm{m}$ and $\log \mathrm{C}$ are normally distributed and there is a strong negative correlation between them [5].

A review of the controversial views on the correlation between coefficient and exponent in the power law equation of fatigue crack growth was studied by Bergner [6]. It is shown that the correlation is an algebraic one that can be suppressed by choosing a particular scaling factor characteristic of the set of materials under investigation. The approach allows the variability of the power law coefficient to be quantified more clearly and the responsible influence factors to be identified.

Crack growth rate has become an important material property for characterizing fatigue crack propagation. From the viewpoint of probabilistic fracture mechanics, the scatter of crack growth rate should be taken into account: in it statistic 
in nature.

Over the years the relationship (1) has continued to be modified to account for a variety of observations, including $\mathrm{R}$ ratio, $\mathrm{K}_{\max }$ effects and crack closure [7].

The objective of the current work is to analyze the two crack growth rate relationships: the Paris equation and a modified Paris equation with the appropriate value of the threshold for crack propagation $\Delta \mathrm{K}_{\mathrm{th}}$ [8]. To this end, an improved direct current potential drop (DCPD) technique is employed to measure fatigue crack initiation and propagation. The material analyzed in the present research is ASTM 148 90-60 cast steel [9], used in railway couplings. To characterize the fractography over the whole range $\Delta \mathrm{K}$, fracture surfaces were prepared for examination, using scanning electron microscopy (SEM).

Methodology of statistic data treatments are discussed. At the end are presents the results of a damage tolerance analysis of these components. A comparative analysis of the results is presented using experimental values obtained for the same material as in service and for the reliability value of $95 \%$ and in similar conditions.

\section{Experimental Details}

\subsection{Material and Test Specimens}

As was said before, an ASTM 148 90-60 cast steel, used in railway couplings of freight is used in this study. Conventional mechanical proprieties are reported in Table 1, together with the parameters of the cyclic curve.

The specimens were of a single edge notched bend type, with dimensions of $20 \mathrm{~mm}$ of width, $10 \mathrm{~mm}$ of thickness, 100 $\mathrm{mm}$ of length and $1 \mathrm{~mm}$ of pre-crack [10]. The six specimens (fig. 1) used in experimental procedure were taken from one of the supplied couplings.

Table 1. Conventional and cyclic mechanical properties for ASTM 148 90-60 cast steel.

\begin{tabular}{ll}
\hline Ultimate stress, UTS [MPa] & $\mathbf{6 5 1 . 0 3}$ \\
\hline Monotonic yield stress, $\sigma_{\mathrm{p} 0.2}[\mathrm{MPa}]$ & 463.95 \\
Elastic modulus, E [GPa] & 207 \\
Elongation at failure, $\mathrm{A}[\%]$ & 28.5 \\
Reduction area, $\mathrm{q}[\%]$ & $47.9 \%$ \\
Cyclic yield stress, $\sigma_{\mathrm{p} 0.2 \mathrm{cyc}}[\mathrm{MPa}]$ & 348 \\
Hardening exponent, $\mathrm{n}$ & 0.177 \\
Hardening coefficient, $\mathrm{k}^{\prime}[\mathrm{MPa}]$ & 1089 \\
\hline
\end{tabular}

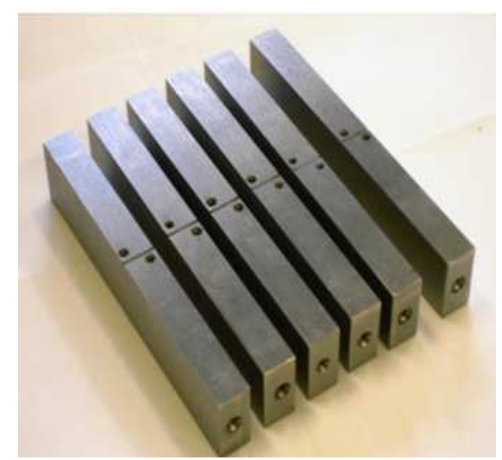

Figure 1. Six test specimens.

\subsection{Experimental Procedure}

Fatigue crack growth tests were performed general according with ASTM standard E647-05 [11]. The bending in three points tests were carried out for a stress ratio of $\mathrm{R}=0.1$, with test temperature and relative humidity recorded but not controlled beyond the room laboratory condition. The cyclic test frequency varied between $10-20 \mathrm{~Hz}$, and the load wave was sinusoidal.

A potential drop technique was used for crack propagation monitoring purposes using a direct current potential drop (DCPD) pulsed system coupled with the controller of the servo hydraulic Dartec M1000/RK testing machine with a capacity of $\pm 100 \mathrm{kN}$. In Figure 2 is presented the test rig.

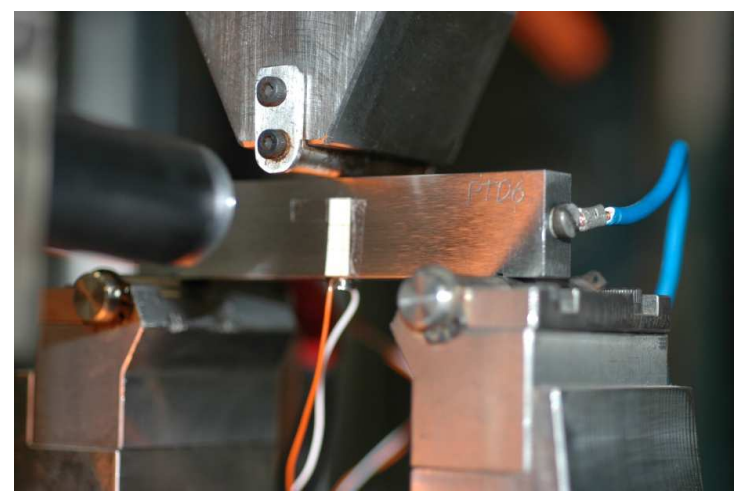

Figure 2. Test rig.

During the tests the loading frequency conditions were changed to produce visible marks on the fracture surface which enable the identification of crack shapes (Fig. 3). For data treatment, 7 points were used along the thickness direction $(10 \mathrm{~mm})$, whose position was obtained with the MAXTSCAN coordinate table.

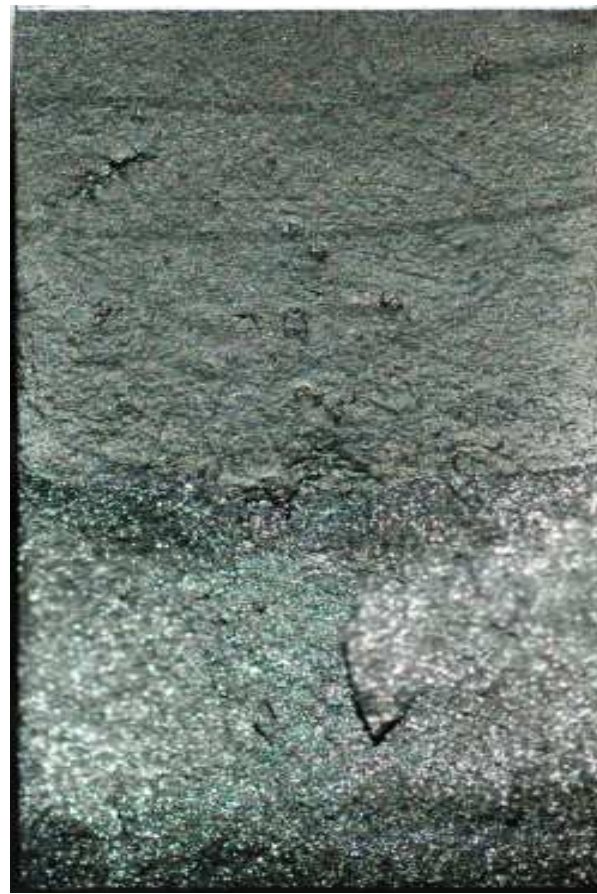

Figure 3. Fracture Surface. 


\subsubsection{Fracture Surface Examination}

Fracture surfaces were prepared for examination using scanning electron microscopy (SEM S-2400 Hitachi), to characterize the fractography over the whole range of $\Delta \mathrm{K}$. This permitted direct comparison of the fracture surface features at values of $\mathrm{da} / \mathrm{dN}$ and $\Delta \mathrm{K}$ in the nearthreshold, intermediate $\Delta K$, and high $\Delta K /$ overload regions for each specimen tested.

Figures 4, 5 and 6 shows SEM fractographs for the fracture surface morphology of the cast steel ASTM148 90-60 at different values of $\Delta \mathrm{K}$. The analysis allowed identifying fatigue striation direction of the crack growth (Fig.4). It is possible also observe portions of the composed surface for alveolar cavities with origin in the cleavage of well visible micro cavities in the Fig. 5, deep secondary cracks called intergranular crack propagation and transgranular cleavages in the zone of progression of the crack are visible can also be observed in this figure. On progressing from the threshold region up through the Paris Law regime and into the overload regime, there was a consistent increase in the amount of cleavage fracture on the fracture surface, as shown in Figs. 4, 5 and 6 , respectively. These morphological characteristics are typical of fatigue fracture surfaces $[11,12]$

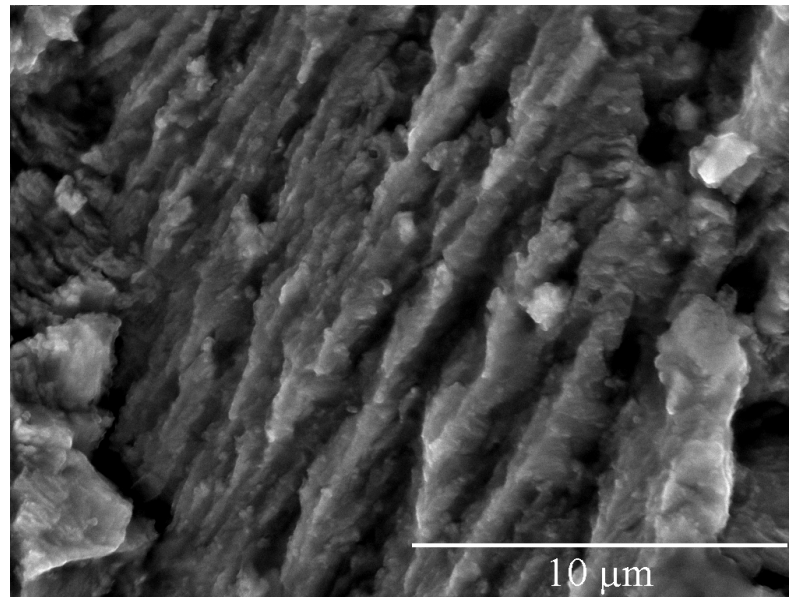

Figure 4. SEM fractography showing typical fracture surface morphology of cast steel ASTM 148 90-60 near threshold, $\Delta K=18.43 \mathrm{MPa} \sqrt{\mathrm{m}}$.

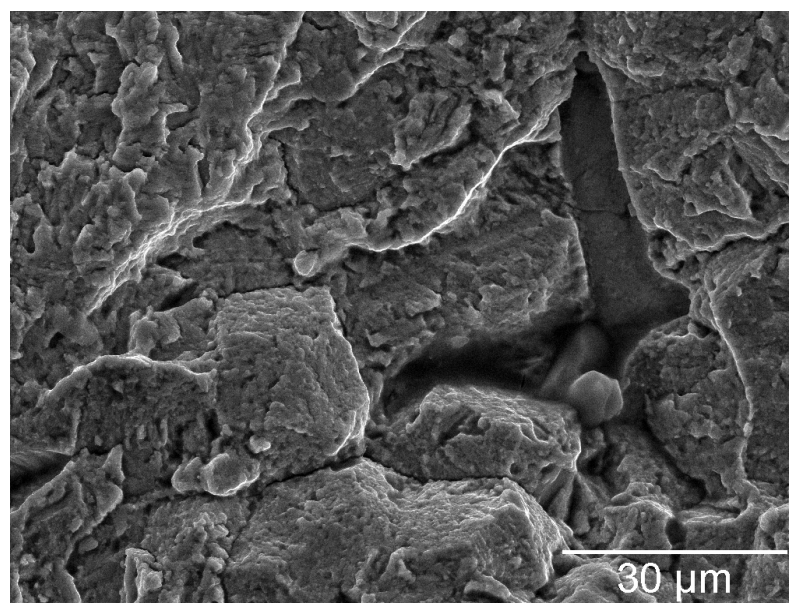

Figure 5. SEM fractography showing typical fracture surface morphology of cast steel ASTM 148 90-60, Paris law regime $\Delta K=21.31 \mathrm{MPa} \sqrt{\mathrm{m}}$.

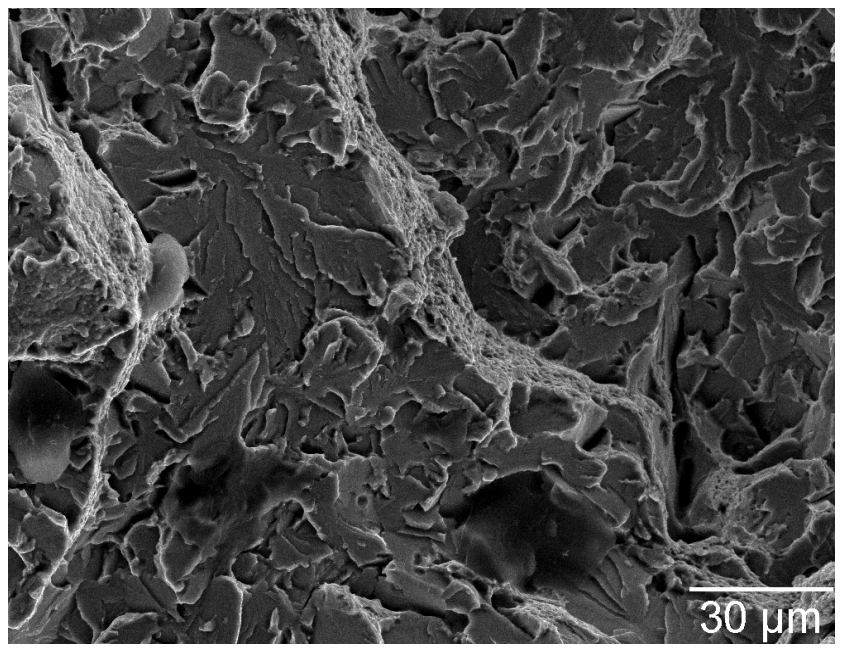

Figure 6. SEM fractography showing typical fracture surface morphology of cast steel ASTM 148 90-60, High $\triangle K=49.5 \mathrm{MPa} \sqrt{\mathrm{m}}$

\subsubsection{Experimental Results}

The calibration curves relate crack size with PD measurements taken near the crack. From calibration curves determined experimentally for each specimen, the propagation curves were obtained (a versus $\mathrm{N}$ ). After that, for different crack lengths values of $\Delta \mathrm{K}$ were obtained.

The stress intensity factor range, $\Delta \mathrm{K}$, was calculated according to following equation (2):

$$
\Delta \mathrm{K}=\mathrm{f}(\mathrm{a} / \mathrm{w}) \times \Delta \sigma \sqrt{\pi \mathrm{a}}
$$

where geometric factor is $\mathrm{f}(\mathrm{a} / \mathrm{w})$, calculated by equation (3) and $\Delta \sigma=\sigma_{\max }-\sigma_{\min }$ is the stress range.

$$
\begin{aligned}
& \mathrm{f}(\mathrm{a} / \mathrm{w})=2.9(\mathrm{a} / \mathrm{w})^{1 / 2}-4.6(\mathrm{a} / \mathrm{w})^{3 / 2}+ \\
& +21.8(\mathrm{a} / \mathrm{w})^{5 / 2}-37.6(\mathrm{a} / \mathrm{w})^{7 / 2}+38.7(\mathrm{a} / \mathrm{w})^{9 / 2)}
\end{aligned}
$$

The da/dN curves were obtained for all the specimens tested. The influence location of PD wire in signal sensitivity can be found on the Ventura works [13]. Secant method was used to calculated da/dN.

The number of points used to calculate $\mathrm{da} / \mathrm{dN}$ using the secant method depended in the quality of the DCPD data, number of points collected and crack propagation speed. The maximum number of points used in this work, to calculate $\mathrm{da} / \mathrm{dN}$, was 13 .

From the viewpoint of probabilistic fracture mechanics, the scatter of crack growth rate should be taken into account. The coefficients of $\mathrm{C}$ and $\mathrm{m}$ of equation (1) are both random variables. In figure 7 the propagation curve of the individual specimen, PT03, can be observed. In this figure regimes I and II can be observed. Notice that $\mathrm{m}$ and $\mathrm{C}$ varies from specimen-to-specimen.

Ichikawa [5] shown that ' $\mathrm{m}$ ' and ' $\log \mathrm{C}^{\prime}$ are normally distributed and there exists a strong negative relation between them. In the next section the statistical methodology for data treatment of parameters " $\mathrm{C}$ " and " $\mathrm{m}$ " is presented. 


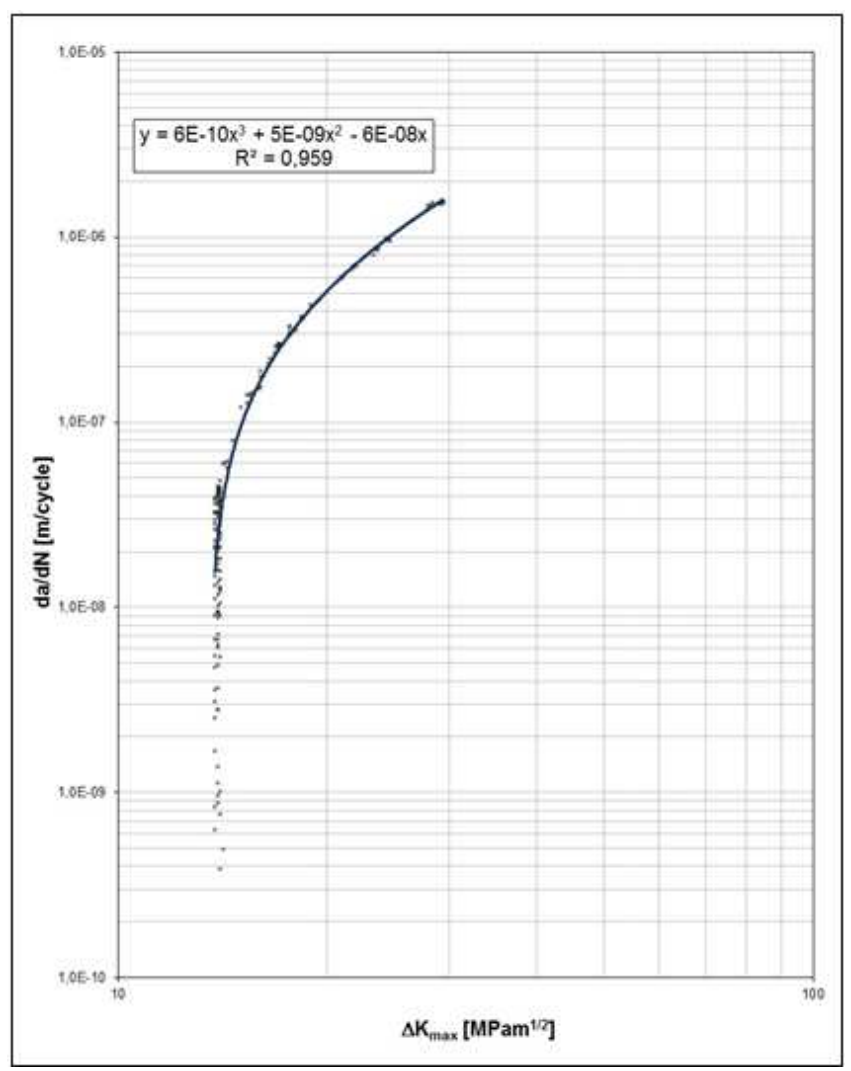

Figure 7. Propagation curve of PT03 specimen.

\section{Probabilistic Models of Experimental Data}

\subsection{Paris Law Parameters}

Tests when there is scatter in the results require a proper statistical treatment. For the purpose of abbreviation the following notation is introduced: $\mathrm{X}=\log (\Delta \mathrm{K})$ and $\mathrm{Y}=\log$ $(\mathrm{da} / \mathrm{dN})$. The geometric representation of the Paris equation is a straight line, given by the expression (4), where $a=\log (C)$ and $\mathrm{b}=\mathrm{m}$ must be estimated from the data points $\left((\mathrm{da} / \mathrm{dN})_{\mathrm{i}}\right.$, $\left.(\Delta \mathrm{K})_{\mathrm{i}}\right), \mathrm{i}=1,2, \ldots, \mathrm{n}$.

$$
\mathrm{Y}=\mathrm{a}+\mathrm{bX}
$$

Log-normal life distribution can be used to determine any probability of failure, Pf. The probability of survival, is defined by equation (5).

$$
P_{s}=1-P_{f}
$$

The figure 8 represents the Paris Law for reliabilities of $95 \%, 90 \%, \% 50 \%, 10 \%$ and $5 \%$. The slope of the propagation curve was obtained for the $\Delta \mathrm{K}=23 \mathrm{MPa} \sqrt{\mathrm{m}}$ and $\Delta \mathrm{K}=32 \mathrm{MPa} \sqrt{\mathrm{m}}$.

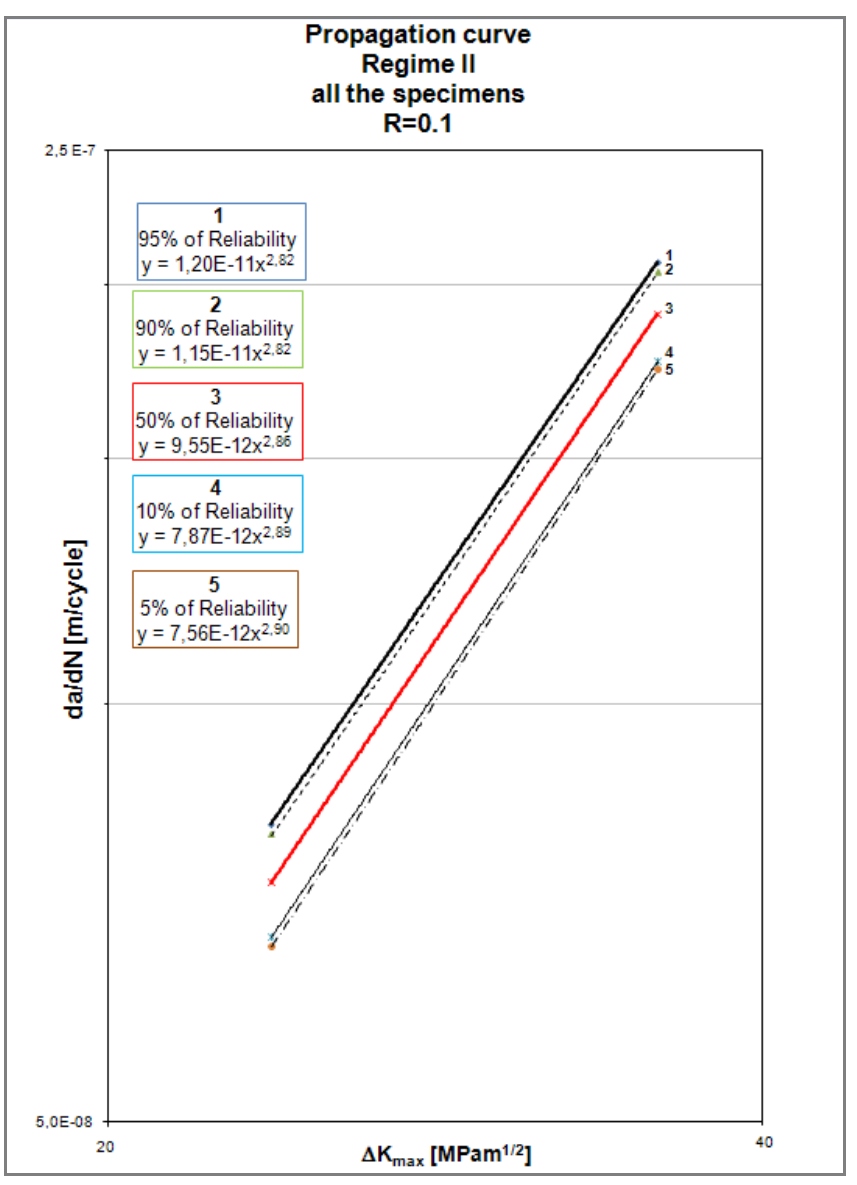

Figure 8. Present the da/dN vs $\Delta K$ curve (Paris Law), obtained from a set of raw data given for treatment of different reliability.

\subsection{Paris Lar Parameters}

Reliability fatigue analysis in these couplings railway, has been conducted [14], where strain gauge data were analyzed and from those data fatigue cycles were derived. The data acquisition was carried out in the most severe predefined journeys in terms of load levels. Continuous acquisition of strain gauges rosettes measurements was carried out over 48 $\mathrm{km}$ in two journeys (loaded and empty wagons). The coupling between the locomotive and the first wagon was selected where higher loads were expected. These components are subjected to characteristic variable amplitude load sequences which have to be account; the stress ratio versus number of accumulated cycles of fatigue diagram for the most critical rosette 6 shows that of a total of 13909 accumulated cycles, $75 \%$ of accumulated cycles are on a stress ratio higher than 0.8 [15].

To attend to the influence of $\mathrm{R}$ ratio effect the following well known, generalized Paris' law is taken into account (equation (6)):

$$
\mathrm{da} / \mathrm{dN}=\mathrm{C}_{0}\left(\Delta \mathrm{K}-\Delta \mathrm{K}_{\mathrm{th}(\mathrm{R}=0)}\right)^{\mathrm{m}_{0}}
$$

Considering the conservator experimental value of threshold of $\Delta \mathrm{K}_{\mathrm{th}(\mathrm{R}=0.1)}=14.02 \mathrm{MPa} \sqrt{\mathrm{m}}$ and using equation (7) with $\mathrm{R}=0.8$, the parameters $\mathrm{C}_{0}$ and $\mathrm{m}_{0}$ of Paris modified law 
are obtained. In figure 9 are represented the propagation curves for reliabilities of $95 \%, 50 \%$ and $5 \%$ with the respectively $\mathrm{C}_{0}$ and $\mathrm{m}_{0}$ material constants.

$$
\Delta \mathrm{K}_{\mathrm{th}(\mathrm{R})}=\Delta \mathrm{K}_{\mathrm{th}(\mathrm{R}=0)}(1-\mathrm{R})
$$

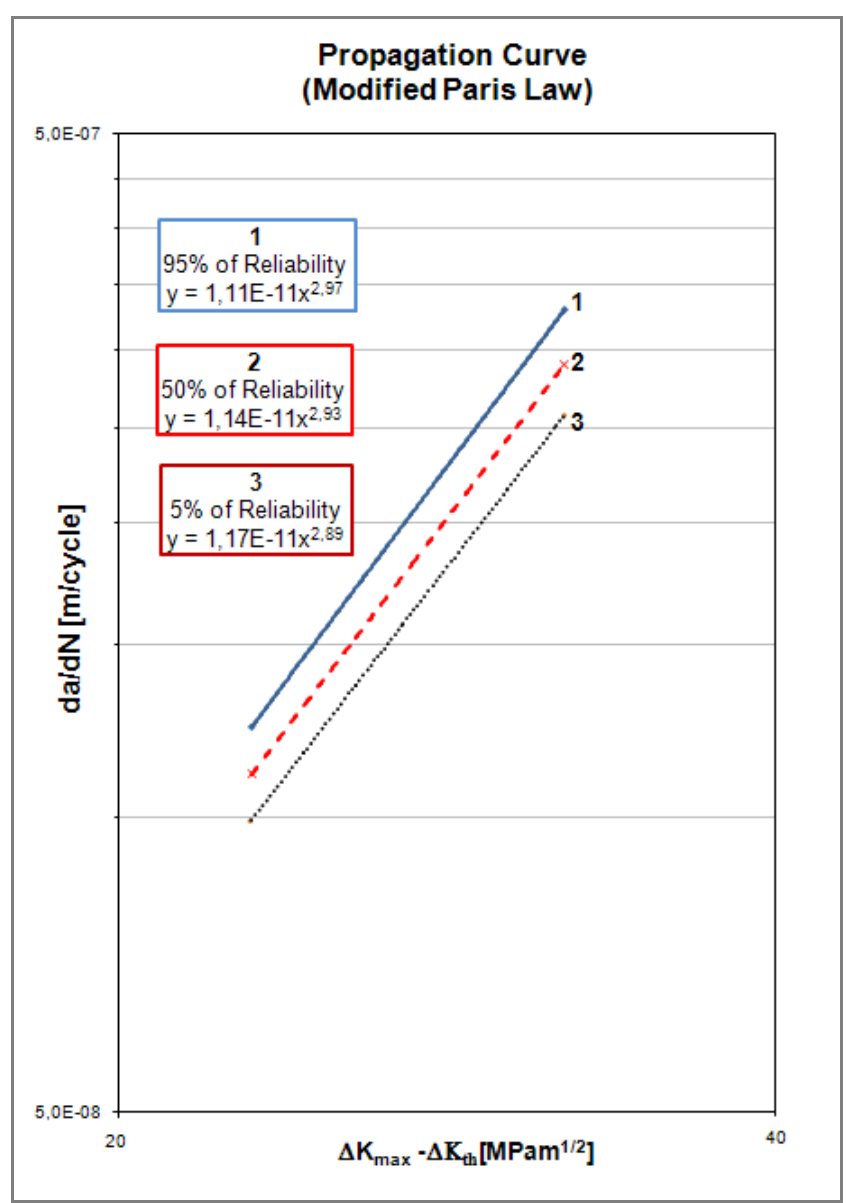

Figure 9. da/dN vs $\Delta K$ curve for Modified Paris Law, obtained from a set of raw data given for treatment of different reliability.

From figures 8 and 9 were obtained the Paris Law (equation (8)) and Modified Paris Law (equation (9)), for reliabilities of $95 \%$.

$$
\begin{aligned}
& \mathrm{da} / \mathrm{dN}=1.20 \mathrm{E}-11(\Delta \mathrm{K})^{2,82}[\mathrm{~m} / \text { cycle; } \mathrm{MPa} \sqrt{\mathrm{m}}] \\
& \mathrm{da} / \mathrm{dN}=1.11 \mathrm{E}-11(\Delta \mathrm{K})^{2,97}[\mathrm{~m} / \text { cycle } ; \mathrm{MPa} \sqrt{\mathrm{m}}]
\end{aligned}
$$

\section{Residual Life Results}

Results of residual life are presented in Figure 10. These curves were obtained for $95 \%$ of reliability propagation curves by Paris and Modified Paris laws. The residual life results in crack propagation from initial defect size of $0,8 \mathrm{~mm}$ located at the radius of curvature between the head and main body of the coupling of the locomotive with the first carriage of the freight train used to carry coal, have shown that:

- 10000 cycles, is the value of fatigue life for crack propagation were obtained with the modified Paris law.
- $\quad 55000$ cycles, is the value of fatigue life for crack propagation were obtained with the Paris law.

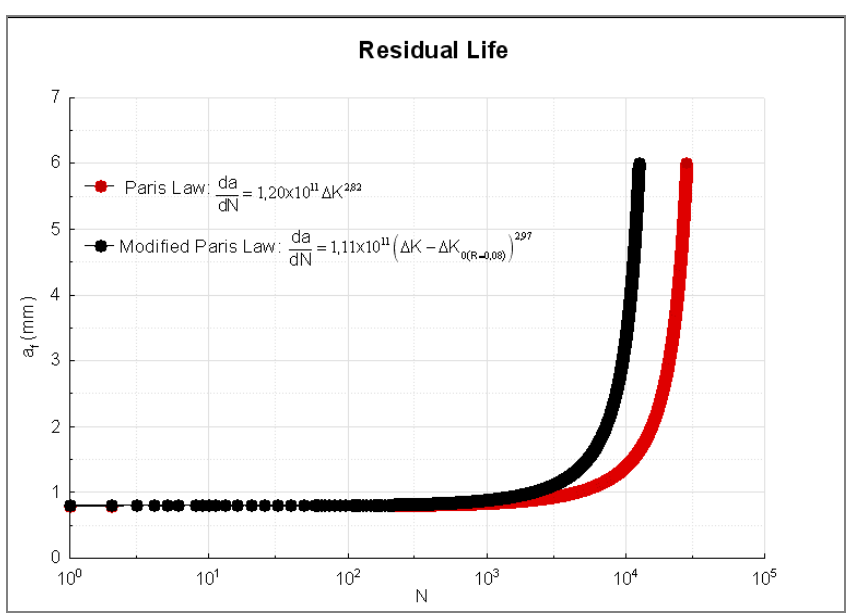

Figure 10. Residual life for fatigue crack propagation.

\section{Conclusions}

For safety it is recommended to use the Modified Paris Law which incorporates the threshold value of the stress intensity factor, $\Delta K_{t h}$, for the appropriate value of the stress ratio, $R$, taking into account the load spectra. The results have shown also that a satisfactory prediction of fatigue life can be made in these components taking into account a damage tolerance phase with a prediction for crack propagation obtained with a Modified Paris Law relationship incorporating the threshold value for crack propagation. This will avoid unnecessary retirement of service at the onset of crack propagation when the results have shown that there still a significant residual life for crack propagation that can be appropriately used to extend with safety the life of these components provided adequate inspection procedures are carried out.

\section{References}

[1] Paris PC, Gomez RE, Anderson WE. A rational analytic theory of fatigue. Trend Eng (1961); 13(1): 9-14.

[2] Liu HW. ASME Trans J Basic Eng (1963); 85D(1): 116-22.

[3] Paris PC, Erdogan F. Critical analysis of crack growth propagation laws. ASME Trans J Basic Eng (1963); 85D(4): 528-34.

[4] Foreman R. G., Kearney V. E., Engle R. M.. Numerical analysis of crack propagation in cyclic-loaded structures. J. Basic Eng. (1967); 89: 459-464.

[5] Ichikawa M. Probabilistic fracture mechanics investigation of fatigue crack growth rate. Statistic Research on Fatigue and Crack, ed. Tsuneshichi Tanaka et. al. London, New York: Elsiever Applied Science (1987); vol. 2: 71-89.

[6] Bergner F., Zouhar G. A new approach to the correlation between the coefficient and the exponent in the power law equation of fatigue crack growth. International Journal of Fatigue 22 (2000): 229-239. 
[7] Schijve J. Fatigue of structures and materials in the 20th century and the state of the art. Int J Fatigue (2003); 25: 679-702.

[8] Ritchie R. D.. Near threshold fatigue crack propagation in steels. Met. Rev. Review 145 (1979); No. 5 and 6: 205.

[9] Infante V., Branco C. M., Brito A. S., Morgado T. L. M. A failure analysis study of cast steel railway couplings used for coal transportation. Engineering Failure Analysis, 10 (2003): 475-489.

[10] BS 5447:1977 (1987). Methods of test for Plane Strain Fracture Toughness $\left(\mathrm{K}_{\mathrm{IC}}\right)$ of Metallic Materials. British Standard Institution.

[11] ASTM E647-05. Standard Test Method for Measurement of Fatigue Crack Growth Rates. Developed by Subcommittee E08.06, Book of Standards Volume 03.01, WestConshohoken, USA.
[12] Hertzberg R. W.. Deformation and Fracture Mechanics of Engineering Materials. 3rd edition. John Wiley \& Sons Inc.. Canada 1989.

[13] ASM Handbook. Volume 19: Fatigue and Fracture. 2nd edition. ASM International. USA. ISBN 10: 0-87170-377-7.

[14] Ventura F.. Inconel 718 Fatigue Crack Propagation at High Temperature. Ph. D Thesis (in Portuguese). Coimbra University. Portugal, 1999.

[15] Morgado T. L. M.. Structural Integrity of a Railway Component Ph. D Thesis (in Portuguese). Lisbon University. Portugal, 2009.

[16] Morgado T. L. M., Branco C. M., Infante V. .Reliability fatigue analysis of Steel Couplings used in railway transport $f$ coal. Second International Conference on Material and Component Performance under Variable Amplitude Loading Proceedings volume II (2009), 715-22. ISBN: 978-3-00-027049-9. 